\title{
Alianças estratégicas no varejo farmacêutico: vantagens e desvantagens na percepção do gestor
}

\author{
Strategic alliances in pharmaceutical retail: advantages and \\ disadvantages from the manager's perception
}

\author{
Bianca Bonassi Ribeiro' \\ Vanderli Correia Prieto ${ }^{2}$
}

\begin{abstract}
Resumo: As alianças são utilizadas pelas empresas para complementar a base de recursos existentes e, assim, viabilizar as suas estratégias. No entanto, sobre esta ação pairam tanto benefícios quanto riscos. Também é necessário definir o tipo de aliança a ser estabelecida, dependendo da adaptação aos interesses comuns e às tendências de mercado. Este estudo tem como objetivo ampliar a compreensão do movimento competitivo que tem se desenvolvido no varejo farmacêutico. O setor apresenta excelente desempenho econômico e perspectiva de continuar crescendo, mas é altamente pulverizado e, por isso, passa por transformações rumo à consolidação. Também são objetivos desta pesquisa identificar os tipos de alianças estratégicas praticadas pelo varejo farmacêutico, bem como as principais vantagens e desvantagens decorrentes desse processo. Para tanto, utiliza-se o método qualitativo de pesquisa, com coleta de dados por meio de entrevistas com dez gestores de diferentes farmácias e drogarias. Os resultados permitiram identificar sete tipos de alianças, as suas vantagens e desvantagens, bem como discutir as mudanças que têm ocorrido no comércio farmacêutico à luz do cenário competitivo atual.
\end{abstract}

Palavras-chave: Aliança estratégica. Decisão estratégica. Varejo farmacêutico. Parcerias estratégicas.

\begin{abstract}
Alliances are used by companies to complement the existing resource base and thus enable their strategies. However, creating alliances involves benefits and risks, and it is also necessary to define the type of alliance to be established depending on the common interests and market trends. Therefore, this study aims to broaden the understanding of the pharmaceutical retail competitive environment. The sector has excellent performance and is expected to continue growing, but it is highly fragmented and therefore has undergone transformations towards consolidation. This research also aims to identify the types of strategic alliances formed by the pharmaceutical retail, as well as the advantages and disadvantages of this process. The qualitative research method was adopted, and the data was collected through interviews with ten pharmacy and drugstore managers. The results showed seven different types of alliances and their advantages and disadvantages. They also helped identify the changes that have occurred in the pharmaceutical trade as a result of its current competitive environment.
\end{abstract}

Keywords: Strategic alliance. Strategic decision. Pharmaceutical retail. Strategic partnerships.

\section{Introdução}

Segundo dados divulgados pelo Conselho Federal de Farmácia - CFF (2012), o Brasil apresentou em dezembro de 2010 o equivalente a 82.204 farmácias e drogarias cadastradas junto aos conselhos regionais de farmácia, sendo o país que possui o maior número de farmácias no mundo e com participação no mercado muito pulverizada. Desse total, 18.598 estão localizadas em capitais e 63.606, em cidades do interior.

O setor apresenta excelente desempenho, com crescimento nas vendas em torno de $10 \%$ ao ano, e as perspectivas são de aumento ainda maior na demanda devido às mudanças no perfil social, econômico e demográfico do brasileiro, como o envelhecimento da população e o aumento do poder aquisitivo da classe "C". O canal farma também tem aumentado a sua participação nas vendas de produtos de higiene e beleza. A concorrência no setor e o aumento da demanda têm impulsionado as farmácias e drogarias a desenvolverem mecanismos que as auxiliem no sentido de melhorar a sua posição competitiva e, consequentemente, aumentarem suas vendas. Atualmente têm se concretizado as mudanças previstas por Machline e Amaral Junior (1998) quanto à

\footnotetext{
Centro de Ciências Sociais e Aplicadas - CCSA, Universidade Presbiteriana Mackenzie, Rua da Consolação, 930, Consolação, CEP 01302-907, São Paulo, SP, Brasil, e-mail: bianca@mackenzie.br

2 Centro de Engenharia, Modelagem e Ciências Sociais Aplicadas, Universidade Federal do ABC - UFABC, Rua Santa Adélia, 166, Bloco A, 7o andar, CEP 09210-170, Santo André, SP, Brasil, e-mail: vanderli.prieto@ ufabc.edu.br
}

Recebido em 7/7/2011 — Aceito em 10/9/2012

Suporte financeiro: Nenhum. 
formação de redes de farmácias. O setor vem passando por profundas mudanças com vistas à consolidação e vem ocorrendo a formação de alianças estratégicas.

Vários argumentos presentes na literatura reforçam os benefícios das alianças estratégicas. Autores tais como Barney (2002), Collis e Montgomery (1997) e Teng (2007) consideram que as alianças são uma alternativa para preencher lacunas internas de recursos e, segundo Ranft e Marsh (2008), principalmente quando há necessidade de se adentrar em um novo mercado. Considera-se, também, que as alianças são uma forma de aumentar a competitividade local e internacional das empresas (THOMPSON; STRICKLAND III, 2001). Jackson e Nelson (2004) avaliam que as alianças são formadas a partir dos mais variados propósitos e contribuem para melhorar a lucratividade da organização, além de desenvolver vantagem competitiva sustentável.

Em contrapartida, possíveis desvantagens das alianças estratégicas também são mencionadas na literatura. Questiona-se, por exemplo, a estabilidade das alianças (INKPEN, 2001), também se mencionam problemas relacionados ao controle do processo decisório (COSTA, 2003; PITTS; LEI, 2003; WALKER, 2004), à dificuldade de compatibilizar a gestão do negócio (THOMPSON; STRICKLAND III, 2001) e, ainda, problemas relacionados à perda de competências (HILL; JONES, 1998; FITZPATRICK; DILULLO, 2005).

$\mathrm{O}$ conceito do que tem sido considerado uma aliança também tem passado por modificações. Até a década de 1980, joint ventures era sinônimo de alianças, mas com o surgimento de novas estruturas e formatos de alianças, elas passaram a se caracterizar a partir de diferentes tipos de acordos colaborativos desenvolvidos por duas ou mais organizações (INKPEN, 2001; RUGMAN; WRIGHT, 2001).

Nesse contexto, o principal objetivo deste estudo é ampliar a compreensão do movimento competitivo que tem se desenvolvido no varejo farmacêutico. Para tanto, foram estabelecidos os seguintes objetivos secundários: (1) identificar os tipos de alianças estratégicas que estão sendo firmadas pelo setor de varejo farmacêutico de pequeno porte; e (2) identificar quais são as principais vantagens e desvantagens dessas alianças.

As vantagens e desvantagens identificadas serão confrontadas com aquelas identificadas na literatura. Desta forma, pretende-se contribuir para a consolidação das propostas já existentes e fornecer subsídios ao tomador de decisão sobre cada uma das alianças estratégicas, uma vez que são decisões complexas que envolvem vulnerabilidade e risco. Outra contribuição esperada está no fato de que o estudo se desenvolve no contexto brasileiro e em um setor que deverá passar, ainda, por grandes transformações. Junto com outros estudos, esta pesquisa poderá ajudar a entender estas mudanças e fazer analogias sobre a teoria e a realidade brasileira.

O presente artigo apresenta, na seção 2, o referencial teórico sobre os tipos de alianças e suas vantagens e desvantagens. Na seção 3, um breve panorama do varejo farmacêutico no Brasil. $\mathrm{Na}$ seção 4, são apresentados os procedimentos metodológicos, a estratégia de pesquisa adotada e, nas seções seguintes, os resultados e as considerações finais.

\section{Referencial teórico}

\subsection{Conceituação e tipos de alianças}

Na visão de Hill e Jones (1998), as alianças são uma alternativa para a diversificação. À medida que duas ou mais empresas se aliam, há uma complementaridade estratégica (INKPEN, 2001), condição esta que faz com que as organizações potencializem suas forças de maneira que possam alcançar metas estratégicas (AAKER, 2001). Portanto, as empresas que estabelecem alianças estratégicas avaliam fatores decisivos relacionados a seus objetivos, mercados e atributos das alianças antes de optar por esse tipo de estratégia (SHAO, 2010).

No que se refere à conceituação de alianças estratégicas, Inkpen (2001) apresenta que, até a década de 1980, joint ventures era sinônimo de alianças. Com o surgimento de novas configurações dessa estratégia, denominam-se alianças os diversos tipos de acordos colaborativos desenvolvidos por duas ou mais organizações (INKPEN, 2001). Basicamente, estes acordos existem para que haja um compartilhamento de custos, riscos, estruturas e benefícios associados a oportunidades de negócios (HILL; JONES, 1998; INKPEN, 2001; BUZÁDY, 2005).

Pitts e Lei (2003) definem alianças como ligações e parcerias entre companhias que pretendem agilizar a obtenção de objetivos econômicos de forma mais eficiente do que poderiam fazer isoladamente. Ojode (2004) entende aliança como o arranjo cooperativo entre organizações para que haja melhor fluxo na utilização dos recursos e/ou estrutura de governança partilhada por empresas autônomas, de forma a alcançar objetivos comuns. Shao (2010) complementa essa visão ao afirmar que, em determinados tipos de negócios e mercados de atuação, essa é a melhor opção se comparada a outras estratégias, como aquisição, que, na concepção dele, não é considerada aliança estratégica e sim outra estratégia.

Jackson e Nelson (2004), por outro lado, preocuparam-se em demonstrar que as alianças se manifestam de diferentes formas, considerando a adaptação dos interesses comuns às novas tendências de mercado, visando impulsionar os investimentos.

Sendo assim, a literatura apresenta diferentes estruturas e configurações que são consideradas 
alianças estratégicas, as quais estão sumarizadas no Quadro 1.

No intuito de enumerar as características elementares das alianças estratégicas, três são citadas por Inkpen (2001): a) os parceiros se mantêm independentes, subsequentemente à formação da aliança; b) as alianças possuem característica de interdependência mútua e uma parte é vulnerável à outra; e c) uma vez que os parceiros permanecem independentes, há uma incerteza quanto ao que uma parte espera da outra.

Ainda para Inkpen (2001), a mensuração do desempenho em uma aliança é muito difícil de ser avaliada e ela poderia ser medida a partir da criação de valor para cada um dos participantes. Valor, no que se refere à competitividade, é definido por Porter (1989) como sendo o montante que os compradores estão dispostos a pagar pelo produto que a empresa oferece; enquanto que para Lowson (2002), adicionar valor está relacionado em quão bem uma organização consegue combinar seus produtos e serviços com as necessidades e escolhas dos clientes.

Valor, para Walker (2004), significa oferecer algo aos clientes de maneira que outras organizações não consigam imitar. Na visão de Vasconcelos e Brito (2004), a capacidade de apropriação do valor criado pela organização é um dos componentes da vantagem competitiva.

\subsection{Vantagens e desvantagens da formação de alianças}

Ao realizar uma aliança estratégica, as organizações envolvidas precisam ter em mente que existem tanto benefícios quanto riscos inerentes a esse tipo de estratégia. Recomenda-se que toda empresa que pretenda estabelecer estratégias de alianças realize um balanço entre cooperação e competição,

Quadro 1. Tipos de alianças estratégicas, elaborado com base na revisão da literatura.

\begin{tabular}{|c|c|c|}
\hline Joint Ventures & $\begin{array}{l}\text { Criação de uma empresa a partir da sociedade } \\
\text { entre duas ou mais organizações, objetivando } \\
\text { atender a interesses comuns. Alternativa } \\
\text { frequente para atuação em outros países. }\end{array}$ & $\begin{array}{l}\text { Collis e Montgomery (1997), Hill e } \\
\text { Jones (1998), Aaker (2001), Inkpen } \\
\text { (2001), Rugman e Wright (2001), } \\
\text { Thompson e Strickland III (2001), } \\
\text { Barney (2002), Grant (2002), Pitts } \\
\text { e Lei (2003), Fitzpatrick e Dilullo } \\
\text { (2005), Buzády (2005) e Prater e } \\
\text { Ghosh (2005). }\end{array}$ \\
\hline Acordos de licenciamento & $\begin{array}{l}\text { Acordo formal firmado entre organizações, } \\
\text { concedendo o direito de utilizar a marca, a } \\
\text { venda de produtos ou uma tecnologia criada e } \\
\text { desenvolvida por uma das partes. }\end{array}$ & $\begin{array}{l}\text { Collis e Montgomery (1997), } \\
\text { Inkpen (2001), Barney (2002), } \\
\text { Costa (2003), Pitts e Lei (2003) e } \\
\text { Buzády (2005). }\end{array}$ \\
\hline $\begin{array}{l}\text { Parcerias entre empresas } \\
\text { não rivais ou empresas que } \\
\text { competem entre si }\end{array}$ & $\begin{array}{l}\text { Forma de garantir melhor eficiência nos } \\
\text { processos operacionais; ambas obtêm vantagem } \\
\text { e benefício com o resultado da aliança. }\end{array}$ & $\begin{array}{l}\text { Costa (2003), Pitts e Lei (2003) e } \\
\text { Buzády (2005). }\end{array}$ \\
\hline $\begin{array}{l}\text { Projetos de desenvolvimento } \\
\text { de produtos }\end{array}$ & $\begin{array}{l}\text { Quando duas ou mais empresas se juntam com } \\
\text { intuito de desenvolver novos produtos }\end{array}$ & $\begin{array}{l}\text { Inkpen (2001), Barney (2002), } \\
\text { Costa (2003), Pitts e Lei (2003) e } \\
\text { Buzády (2005). }\end{array}$ \\
\hline $\begin{array}{l}\text { Compartilhamento de } \\
\text { compras e/ou produção }\end{array}$ & $\begin{array}{l}\text { Empresas que se juntam para ganhar maior } \\
\text { poder diante dos fornecedores ao compartilhar } \\
\text { compras, ou ganhar escala e reduzir custos ao } \\
\text { compartilhar a produção. }\end{array}$ & $\begin{array}{l}\text { Inkpen (2001), Barney (2002), } \\
\text { Costa (2003), Buzády (2005) e } \\
\text { MaCGregor e Vrazalic (2005). }\end{array}$ \\
\hline Operações logísticas & $\begin{array}{l}\text { Alianças envolvendo o processo de } \\
\text { distribuição e transporte }\end{array}$ & Ratten (2004) e Buzády (2005). \\
\hline $\begin{array}{l}\text { Terceirização ou } \\
\text { subcontratação }\end{array}$ & $\begin{array}{l}\text { Acordos entre duas ou mais empresas para } \\
\text { execução de certas atividades inerentes ao } \\
\text { processo e operacionalização de uma empresa }\end{array}$ & $\begin{array}{l}\text { Costa (2003), Pitts e Lei (2003) e } \\
\text { Fitzpatrick e Dilullo (2005). }\end{array}$ \\
\hline Aquisições & Compra de uma empresa por outra organização & Costa (2003) e Buzády (2005). \\
\hline Franquias & $\begin{array}{l}\text { Sistema de expansão baseado no pagamento de } \\
\text { royalty ao franqueador por parte do franqueado }\end{array}$ & $\begin{array}{l}\text { Collis e Montgomery (1997), Costa } \\
(2003), \text { Jacobsen (2004) e Buzády } \\
(2005) .\end{array}$ \\
\hline Aliança horizontal & $\begin{array}{l}\text { Marcada pelos acordos entre empresas ainda } \\
\text { que elas concorram entre si em um mesmo } \\
\text { mercado, proporcionando o mútuo aumento de } \\
\text { competitividade. }\end{array}$ & Ojode (2004). \\
\hline
\end{tabular}


ponderando sobre os custos de coordenação, os custos de aprendizado, bem como os custos da inflexibilidade, para decidir sobre a sua viabilidade ou não (PITTS; LEI, 2003).

Outro aspecto importante a ser avaliado pelas empresas participantes está em verificar que as diferenças entre tais firmas não devem ser confundidas com incompatibilidades entre si (COSTA, 2003). Este mesmo autor ainda menciona a importância em avaliar se as instituições que formarão a aliança possuem compatibilidade quanto a princípios, valores, modus operandi e demais estratégias, para que não haja divergências discrepantes e perda de competitividade.

No que se refere às vantagens das alianças estratégicas, tem-se que elas servem como uma opção para agregar valor às atividades de um negócio (INKPEN, 2001; JACKSON; NELSON, 2004; WALKER, 2004). Para Barney (2002), as alianças estratégicas possibilitam às empresas desenvolver cooperação e também ter condições de operar múltiplas formas de negócios, simultaneamente. Neste mesmo contexto, Jackson e Nelson (2004) avaliam que as alianças emergem pelos mais variados propósitos, contribuindo para um melhor desempenho e lucratividade da organização, de maneira a auxiliar na obtenção e desenvolvimento da vantagem competitiva sustentável.

Outra possível vantagem é a possibilidade de as empresas desenvolverem uma plataforma para o aprendizado organizacional (INKPEN, 2001). Nesse sentido, Ratten (2004) afirma que as alianças auxiliam no processo de aprendizado e troca de informações ao longo da cadeia de suprimentos, propiciando melhor dinâmica e gerenciamento entre as diversas empresas envolvidas. Quando a colaboração ocorre entre a empresa e seus fornecedores, a boa perspectiva está em gerar um aumento na margem de lucros (NORDIN, 2004; JACKSON; NELSON, 2004).

As principais vantagens que condicionam a implementação de alianças estratégicas, encontradas na literatura estudada, estão resumidas na sequência: a) transferência e desenvolvimento de tecnologia - as alianças proporcionam um incentivo e aprimoramento em tecnologias (AAKER, 2001; COSTA, 2003; INKPEN, 2001; MaCGREGOR; VRAZALIC, 2005; PITTS; LEI, 2003; THOMPSON; STRICKLAND III, 2001; WALKER, 2004); b) acesso de mercado - as alianças auxiliam na expansão, principalmente em termos geográficos (AAKER, 2001; BARNEY, 2002; MaCGREGOR; VRAZALIC, 2005; PITTS; LEI, 2003; WALKER, 2004); c) geração de economias de escala - a partir de grandes volumes produzidos e comercializados (AAKER, 2001; BARNEY, 2002; GRANT, 2002; INKPEN, 2001;THOMPSON; STRICKLAND III, 2001); d) influência na estrutura da indústria - permite a separação de competidores em clusters e afetam toda a estrutura da indústria (COSTA,
2003; JACKSON; NELSON, 2004; NORDIN, 2004; WALKER, 2004).

Segundo Rugman e Wright (2001), as alianças existem para satisfazer, ao menos, um dos seguintes propósitos: I) fortalecer um negócio existente; II) introduzir os produtos de uma empresa em novos mercados; III) obter produtos que podem ser comercializados em mercados existentes; e/ou IV) diversificar em novos negócios.

As principais vantagens para uma organização ao firmar uma aliança estratégica estão representadas pela Figura 1.

No levantamento teórico realizado para este estudo, também foram identificadas as desvantagens ao desenvolver alianças estratégicas.

Autores como Inkpen (2001) e Liu (2009), embora reconheçam as vantagens das alianças estratégicas, também questionam o seu poder para de fato gerar vantagem competitiva. Liu (2009) ressalta que os envolvidos nas alianças podem se tornar futuros competidores por terem tido fácil acesso a mercados e terem obtido tecnologia a baixo custo. Em um estudo realizado por Inkpen (2001), verificou-se que cerca de $50 \%$ das alianças se encontravam instáveis, ponto este também retratado por Liu (2009). A mesma pesquisa revelou que mesmo as alianças bem sucedidas apresentavam tendência para o rompimento, sendo as principais razões: inflexibilidade de gestão, quebra de confiança, problemas com a troca de informações, conflitos entre as partes e perda de continuidade de gestão e expectativas diferentes de cada participante. Com base nos resultados do seu estudo, Liu (2009) afirma que as alianças estratégicas podem deixar os participantes instáveis e vulneráveis no que tange à vantagem competitiva.

Thompson e Strickland III (2001) também listam algumas razões que podem gerar o rompimento da parceria, e que são: divergência de objetivos e prioridades, inabilidade de trabalhar bem em conjunto e surgimento de tecnologias mais atraentes.

As principais desvantagens identificadas na revisão de literatura estão identificadas no Quadro 2 e devem servir de base para os principais cuidados que as organizações devem ter ao intencionar estabelecer uma aliança estratégica.

\section{O varejo farmacêutico no Brasil}

O varejo farmacêutico surgiu no Brasil, de acordo com o Conselho Regional de Farmácia do Estado de São Paulo - CRF-SP (2011), no século X com as boticas, que, por meio dos seus profissionais, os boticários, eram os lugares onde se diagnosticava a doença, preparavam-se e armazenavam-se os medicamentos.

Atualmente existem as farmácias e drogarias que são a evolução das antigas boticas. A denominação drogaria foi criada pela Lei $\mathrm{N}^{\circ} 5.991$ de 17/12/1973, 


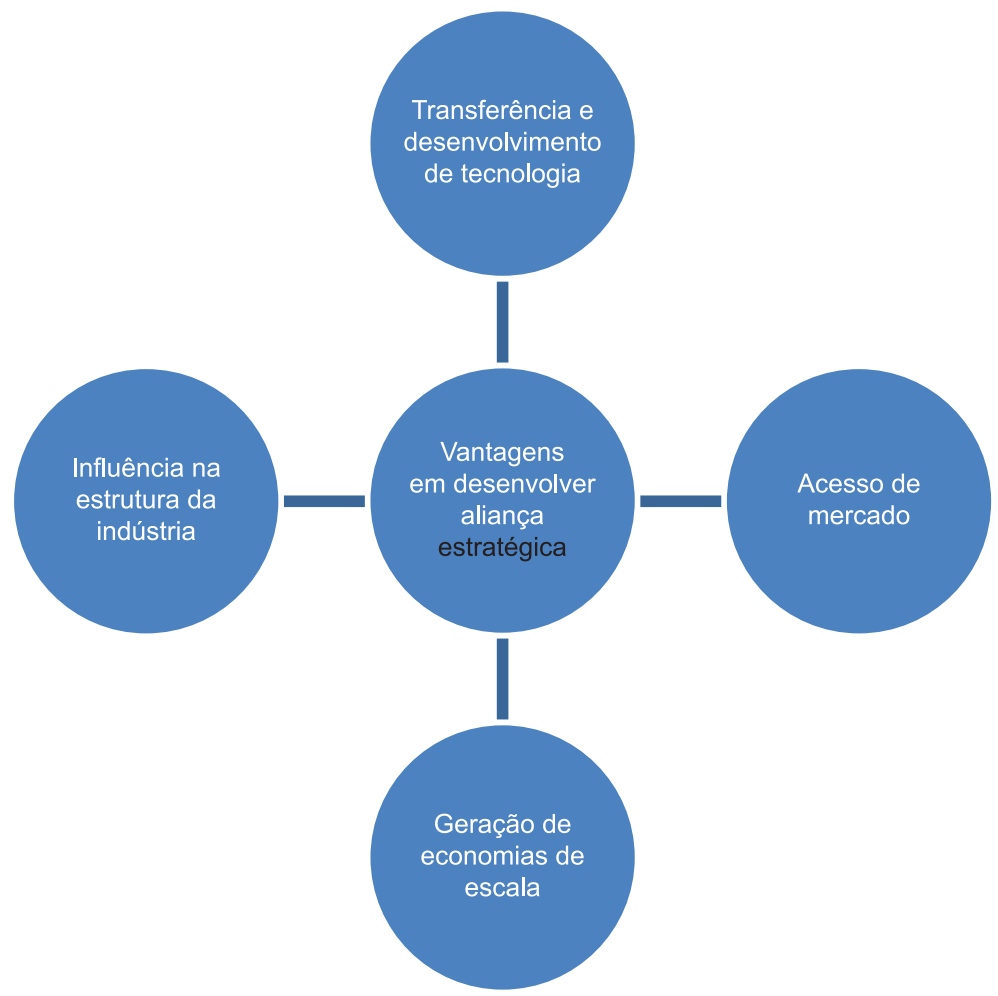

Figura 1. Síntese das vantagens em desenvolver aliança estratégica, elaborada com base na revisão de literatura.

Quadro 2. Desvantagens das alianças estratégicas, elaborado com base na revisão de literatura.

\begin{tabular}{|l|l|}
\hline Diminuição de controle & $\begin{array}{l}\text { O processo decisório conta com mais envolvidos e menor poder de cada um, } \\
\text { aumentando a dificuldade de estabelecer objetivos comuns (COSTA, 2003; } \\
\text { PITTS; LEI, 2003; WALKER, 2004). }\end{array}$ \\
\hline Inflexibilidade estratégica & $\begin{array}{l}\text { O direcionamento estratégico se torna mais lento e engessado (COSTA, 2003; } \\
\text { WALKER, 2004). }\end{array}$ \\
\hline $\begin{array}{l}\text { Enfraquecimento da identidade } \\
\text { organizacional }\end{array}$ & $\begin{array}{l}\text { A construção da identidade está baseada no consistente controle sobre o } \\
\text { desempenho da empresa. A partir do momento em que há outro envolvido, a } \\
\text { identidade de ambos tende a se fundir, prevalecendo a mais forte (THOMPSON; } \\
\text { STRICKLAND III, 2001). }\end{array}$ \\
\hline $\begin{array}{l}\text { Perda de competências internas } \\
\text { e conhecimento intelectual }\end{array}$ & $\begin{array}{l}\text { O compartilhamento de formas de atuação pode gerar a transferência de } \\
\text { um conhecimento para outra empresa e acarretar desvantagens futuras } \\
\text { (FITZPATRICK; DILULLO, 2005; HILL; JONES, 1998). }\end{array}$ \\
\hline $\begin{array}{l}\text { Crescimento de } \\
\text { incompatibilidades entre } \\
\text { parceiros }\end{array}$ & $\begin{array}{l}\text { Ao longo do tempo, é possível que as empresas se tornem muito diferentes e } \\
\text { desenvolvam objetivos e estratégias distintas (COLLIS; MONTGOMERY, 1997; } \\
\text { PITTS; LEI, 2003). }\end{array}$ \\
\hline Questões antitruste & $\begin{array}{l}\text { As alianças, especialmente entre concorrentes, sofrem com as questões antitruste. } \\
\text { O governo tenta evitar o surgimento de competidores dominantes em uma } \\
\text { indústria (WALKER, 2004). }\end{array}$ \\
\hline
\end{tabular}

promulgada pela Agência Nacional de Vigilância Sanitária - ANVISA (1973), classificando estabelecimentos aptos apenas à comercialização de medicamentos e correlatos em suas embalagens originais, não sendo permitida a manipulação. Às farmácias é permitida a manipulação de fórmulas magistrais e oficiais, comércio de drogas, medicamentos, insumos farmacêuticos e correlatos.
As drogarias são empresas pertencentes ao varejo da indústria farmacêutica e se enquadram na classificação de lojas de produtos diferenciados (LEVY; WEITZ, 2000) e concentram produtos ligados à saúde e cuidados pessoais.

$\mathrm{O}$ varejo farmacêutico brasileiro apresenta excelentes resultados na opinião dos especialistas. Entre março de 2010 e abril de 2011, o setor 
movimentou R \$ 37,7 bilhões e fechou o ano de 2011 com faturamento total de $\mathrm{R} \$ 41$ bilhões. A estimativa para o setor até 2015 é de uma taxa de crescimento anual sempre na casa dos dois dígitos, em torno de $10 \%$ ao ano (IMS HEALTH..., 2012).

Uma estimativa da Associação Brasileira de Redes de Farmácias e Drogarias (Abrafarma) aponta que o Brasil caminha para ser, ainda em 2015, o quinto maior mercado mundial - hoje, é o sétimo (BARRETO, 2012).

Nos últimos 8 anos (2003-2011), o mercado cresceu o dobro do crescimento do PIB brasileiro. Na última década, o PIB brasileiro dobrou, ao passo que os números do mercado farmacêutico quadruplicaram (TAMASCIA, 2012).

Segundo Barreto (2012), o mercado brasileiro de medicamentos movimentou, em vendas, $\mathrm{R} \$ 24$ bilhões em 2008, passando para $\mathrm{R} \$ 43,9$ milhões no ano de 2011, uma evolução de 82,91\%.

Esse forte crescimento tem sido influenciado por vários fatores, tais como a expansão econômica brasileira, com estabilidade nos principais índices, como inflação e PIB; aumento do emprego formal, melhoria na distribuição de renda e ascensão social, envelhecimento da população, queda de patentes, migração de volumes do institucional para o varejo pelo programa Aqui tem Farmácia Popular e a inovação, criando novos formatos de lojas que atendem às características de cada região (BARRETO, 2012).

Outro fator que impulsiona o crescimento é o aumento do número de consumidores que estão adquirindo produtos pessoais pelo canal farma. De acordo com estudo realizado pela Nielsen Brasil (NIELSEN..., 2010), 41,5\% do faturamento da cesta de Higiene e Beleza em 2009 veio do canal Farma, $7 \%$ a mais do que os $34,5 \%$ registrados em 2002 . O varejo farmacêutico é o segundo colocado em termos de importância no faturamento total da cesta, atrás dos autosserviços, que detêm 52,7\%. As farmácias e drogarias representam 57\% do faturamento de produtos de Higiene e Beleza tipo Premium, enquanto que no autosserviço, esse índice é de 32\%.

Mudanças, como a das leis que restringiam a exposição dos Mips (Medicamentos isentos de prescrição), são um fator que contribui para que estas categorias cresçam no canal (NIELSEN..., 2010).

Apesar da força dos itens de maior preço, os consumidores dos níveis socioeconômicos C, D+E são responsáveis por mais de $50 \%$ dos gastos em todas as redes de farmácias e drogarias (NIELSEN..., 2010).

Os itens de higiene e beleza devem continuar a impulsionar as vendas no canal farma, uma vez que o Brasil é o terceiro país em que mais se consome esses artigos no mundo e tem apresentado taxas de crescimento superiores a $10 \%$ em 2009 e 2010 e de $8,8 \%$ em 2011. Segundo o Euromonitor, caso seja mantido o ritmo de crescimento previsto para os próximos anos no Brasil, em 2013 o País deve superar o Japão, o segundo colocado no ranking mundial, atrás dos Estados Unidos (CARMO, 2011).

Paralelamente aos índices de crescimento do setor, o varejo farmacêutico passa por transformações significativas.

Existem hoje no País 82.204 farmácias e drogarias, sendo 18.598 em capitais e 63.606 em cidades do interior (CONSELHO..., 2012). O mercado é extremamente pulverizado; as quatro líderes têm apenas $25 \%$ de participação, sendo que, no mercado americano, as quatro maiores dominam $60 \%$ das vendas.

Com o aumento da demanda, grandes redes têm buscado formas de se capitalizar e ampliar sua visibilidade e, para tanto, o mercado tem passado por fusões e aquisições em rumo à consolidação do setor. Um exemplo desse movimento são as fusões das redes Raia e Drogasil e Pacheco e São Paulo, criando os maiores grupos do setor, com vendas superiores a 4 bilhões de reais (AMORIM, 2012).

O processo de consolidação é uma tendência e, segundo especialistas, diversas redes regionais estão sendo avaliadas por especialistas. As principais empresas do mundo têm interesse em entrar no País, uma vez que não há mais espaço para crescer na Europa e nos Estados Unidos (AMORIM, 2012).

As vantagens e desvantagens das alianças estratégicas serão sumarizadas na seção metodológica e deverão fazer parte do roteiro de entrevistas e da análise dos dados, assim como o levantamento teórico sobre o varejo farmacêutico será aplicado na análise do movimento competitivo do setor.

\section{Procedimentos metodológicos}

Com o propósito de alcançar os objetivos propostos neste trabalho, utilizou-se o método de pesquisa qualitativo para a coleta e análise dos dados, cujo emprego justifica-se pela possibilidade de identificar os fenômenos na perspectiva dos envolvidos (KÖCHE, 1999).

Os dados foram coletados junto aos gestores de farmácias e drogarias localizadas nas cidades de Bragança Paulista e Atibaia, pertencentes à Região Bragantina, no Estado de São Paulo. A região escolhida está localizada no eixo que contempla cidades que estão entre as maiores do Brasil: São Paulo, Rio de Janeiro e Minas Gerais. As cidades selecionadas estão entre as 60 maiores do interior do Estado de São Paulo e possuem mais de 100.000 habitantes. A importância comercial da região faz com que o varejo farmacêutico seja afetado pelas mudanças que estão acontecendo no ambiente competitivo dos negócios e, em decorrência disso, ocorrem as alianças estratégicas, objeto desta pesquisa.

As empresas objeto da pesquisa, com estruturas menores, propiciaram mais acessibilidade aos gestores. 
Ainda assim, as farmácias e drogarias se mostraram resistentes ao fornecimento de informações, com receio da transmissão de informações para a concorrência.

$\mathrm{O}$ procedimento para a coleta dos dados seguiu três etapas. Em um primeiro momento, entrou-se em contato pessoalmente e por telefone com 32 farmácias e drogarias nas cidades de Bragança Paulista e Atibaia. Entre as empresas contatadas, 21 farmácias e drogarias praticavam algum tipo de aliança estratégica e se enquadravam no escopo da pesquisa.

O segundo passo da coleta de dados foi estabelecer um primeiro vínculo com o proprietário ou gestor da organização fazendo a identificação dos entrevistadores, bem como a apresentação e explicação da pesquisa. Depois desta identificação e apresentação, foi solicitada a colaboração dos donos ou gestores das farmácias e/ou drogarias concedendo um horário para que fosse agendada uma entrevista em profundidade. De todas as 21 farmácias e drogarias que praticavam algum tipo de aliança estratégica, apenas 12 aceitaram colaborar com o estudo em questão. No decorrer do período, entre o primeiro contato e a data da entrevista, duas drogarias optaram por desistir de participar da pesquisa, cancelando então as entrevistas.

$\mathrm{Na}$ terceira etapa, foram realizadas as entrevistas em profundidade e a coleta de dados a partir de um roteiro de entrevista semiestruturado, baseado no referencial teórico, conforme exposto na matriz de amarração demonstrada pela Figura 2.

Objetivo: Identificar, por meio da opinião do gestor, quais são as principais vantagens e desvantagens para o varejista farmacêutico, ao firmar uma ou mais alianças estratégicas

\begin{tabular}{|c|c|c|}
\hline & & \\
\hline $\begin{array}{l}\text { Van } \\
\checkmark \\
\checkmark \\
\checkmark \\
\\
\\
\checkmark \\
\\
\checkmark \\
\checkmark \\
\checkmark \\
\checkmark \\
\text { Font } \\
\text { Inkp } \\
\text { Wall } \\
(200 \\
(200\end{array}$ & $\begin{array}{l}\text { Opção para agregar valor às atividades de um } \\
\text { negócio. } \\
\text { Operar múltiplas formas de negócios, } \\
\text { simultaneamente. } \\
\text { Melhor desempenho e lucratividade da } \\
\text { organização, de maneira a auxiliar na obtenção e } \\
\text { desenvolvimento da vantagem competitiva } \\
\text { sustentável. } \\
\text { D esenvolver uma plataforma para o aprendizado } \\
\text { organizacional e troca de informações ao longo } \\
\text { da cadeia de suprimentos. } \\
\text { Transferência e desenvolvimento de tecnologia. } \\
\text { Acesso de mercado. } \\
\text { Geração de economias de escala. } \\
\text { Influência na estrutura da indústria. } \\
\text { Aaker (2001); Thompson; Strickland (2001); } \\
\text { (2001); Pitts; Lei (2003); Costa (2003); } \\
\text { ). }\end{array}$ & $\begin{array}{cl}\text { Desvantagens } \\
\checkmark & \text { Diminuição de controle. } \\
\checkmark & \text { Inflexibilidade estratégica. } \\
\checkmark & \text { Enfraquecimento da } \\
& \text { identidade organizacional. } \\
\checkmark & \begin{array}{l}\text { Perda de competências } \\
\text { internas e conhecimento }\end{array} \\
& \text { intelectual. } \\
\checkmark & \text { Crescimento de } \\
& \text { incompatibilidades entre } \\
& \text { parceiros. } \\
\checkmark & \text { Questões antitrustes. } \\
\checkmark & \text { Eventual perda de vantagem } \\
& \text { competitiva. } \\
\text { Fonte: } & \text { Pitts; Lei (2003); Costa (2003); } \\
\text { Walker (2004); Thompson; Strickland } \\
\text { (2001); Hill; Jones (1998); Fitzpatrick; } \\
\text { Dilullo (2005); Collis; Montgomery } \\
\text { (1997); Liu (2009). }\end{array}$ \\
\hline & $\downarrow$ & $\downarrow$ \\
\hline 1. & $\begin{array}{l}\text { Perguntas do roteiro } \\
\text { Pela sua experiência, você acredita que todos os } \\
\text { que sentido? Por quê? }\end{array}$ & na: \\
\hline $\begin{array}{l}2 . \\
3 .\end{array}$ & $\begin{array}{l}\text { Enumere os pontos fortes e fracos das alianças } p \\
\text { Você acredita que depois de estabelecer as alian } \\
\text { diminuiu? }\end{array}$ & $\begin{array}{l}\text { cor sua farmácia/ drogaria. } \\
\text { controle sobre a empresa }\end{array}$ \\
\hline 4. & $\begin{array}{l}\text { Você identificou alguma diferença em termos de } \\
\text { foram? }\end{array}$ & Ss desenvolver a aliança? Quais \\
\hline 5. & Como se deu a escolha dos participantes da aliar & \\
\hline 6. & $\begin{array}{l}\text { Existe algum tipo de conflito/ desentendimento } \\
\text { você poderia comentar? }\end{array}$ & articipantes? Em caso afirmativo, \\
\hline
\end{tabular}

Figura 2. Matriz de amarração. 
As entrevistas foram realizadas nas próprias farmácias ou drogarias e foram devidamente registradas. Também foram registradas algumas observações dos entrevistadores, tais como: receptividade e compreensão à pergunta; direção dos olhos e gesticulação; ansiedade ou receio; entre outros aspectos relevantes à posterior análise. As entrevistas foram transcritas de forma a facilitar o processo de análise e interpretação dos dados.

Quanto à estrutura das farmácias e drogarias analisadas, duas atuam sob a forma de franquias, uma se caracteriza como integrante de uma associação de farmácias independentes - cooperativa - e possui seis lojas (pontos de venda). Também fizeram parte do estudo duas pequenas redes locais possuindo cinco e seis lojas cada uma, e, por fim, cinco empresas eram farmácias e drogarias independentes.

Os dados foram analisados empregando-se a técnica de análise de conteúdo, como proposta por Bardin (1977) e detalhada a seguir.

A pré-análise consiste em escolher os documentos que serão analisados e estabelecer os objetivos e indicadores que fundamentem a interpretação final (BARDIN, 1977).

Nesta pesquisa, o material a ser analisado refere-se às respostas das entrevistas realizadas com os gestores. No momento da pré-análise, foi feita uma leitura flutuante do material compilado e selecionados os dados adequados ao estudo e aos seus objetivos.

A exploração do material é a segunda grande etapa que engloba a análise de conteúdo, nela são realizados operações e procedimentos de codificação e categorização do material, em função das regras previamente formuladas (BARDIN, 1977). Neste estudo, tem-se que o recorte que delimita o material em estudo é o tipo e a quantidade de alianças estratégicas praticadas pelas farmácias e drogarias estudadas, bem como as vantagens e desvantagens identificadas pelos gestores.

A terceira etapa do método de análise de conteúdo é a análise e interpretação dos resultados. Neste estudo a análise foi qualitativa, por meio da discussão das vantagens e desvantagens apontadas pelos gestores à luz dos conceitos apresentados no referencial teórico e sumarizados como proposta de pesquisa pela matriz de amarração já apresentada na Figura 2.

\section{Apresentação e análise dos resultados}

Identificou-se que cada empresa pesquisada pratica, em média, três tipos de alianças estratégicas. Os tipos de alianças praticados, bem como as vantagens e desvantagens, estão demonstrados no Quadro 3 e serão analisados a seguir.

Com relação às franquias, verificou-se que esse tipo de aliança estratégica estabelece e transmite aos clientes padrões de qualidade que se tornam fundamentais em um ramo de atividade em que os consumidores são leigos e dependem da confiança no estabelecimento para aceitarem e se submeterem aos serviços prestados pela farmácia. Algumas evidências neste sentido são o know-how no desenvolvimento de fórmulas, os fornecedores previamente homologados que asseguram a qualidade dos produtos e a marca que, por ser conhecida, tem potencial para gerar lealdade de clientes (ver Quadro 3). Estas evidências têm relação com o que Inkpen (2001), Jackson e Nelson (2004) e Walker (2004) descrevem como vantagem de uma aliança, ou seja, a possibilidade de agregar valor às atividades de uma organização ou, ainda, à afirmação de Ojode (2004) de que uma aliança se justifica quando além de criar valor contribuir para o compartilhamento de recursos.

Quanto às desvantagens, os relatos referem-se à inflexibilidade de gestão, problemas com trocas de informações e expectativas diferentes entre os franqueadores e franqueados, problemas estes pontuados por Costa (2003), Pitts e Lei (2003) e Walker (2004) - ver Quadro 2. Este resultado também corrobora a afirmação de Inkpen (2001) quanto ao risco de que mesmo as alianças bem sucedidas acabem por problemas desse tipo, relacionados à gestão.

As competências internas e conhecimento intelectual podem se perder quando uma organização transmite à outra sua forma de atuação, seu know-how e sua tecnologia (FITZPATRICK; DILULLO, 2005; HILL; JONES, 1998), este é o maior problema das franquias, principalmente quando os resultados demonstram que os franqueados sentem que já possuem o conhecimento necessário para uma atuação sem o suporte do franqueador.

No processo de análise dos resultados, outra constatação relevante está atrelada à falta ou perda de controle em dois tipos de alianças: franquias e associação de drogarias independentes (popularmente denominadas cooperativas pelos gestores). Embora a resposta à pergunta Você acredita que depois de estabelecer as alianças, o seu controle sobre a empresa diminuiu? tenha sido negativa, os respondentes fizeram questão de explicitar o descontentamento e o desânimo diante da perda de autonomia no processo decisório. Esta mensagem foi percebida no decorrer da entrevista, principalmente quando os respondentes citavam os pontos fracos das alianças e quando, no caso das franquias, os entrevistados respondiam que não abririam uma franquia novamente. Porém todos foram unanimes em enfatizar que seja franquia ou associação de drogarias independentes proporcionavam maior diferenciação junto aos clientes em virtude da marca conhecida.

Tanto no caso das franquias quanto no caso das compras compartilhadas ou associativismo, o compartilhamento de riscos e diminuição de custos 


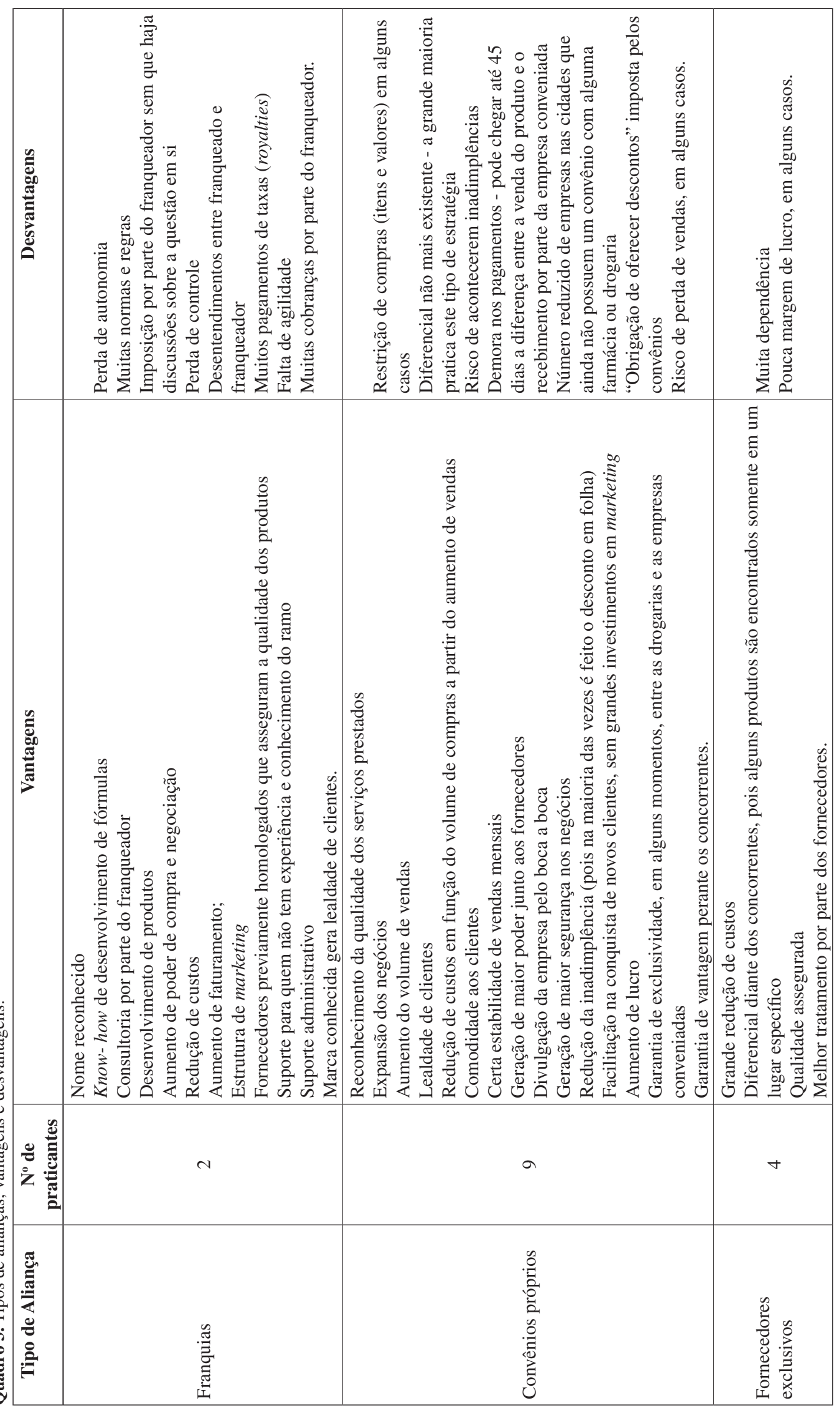




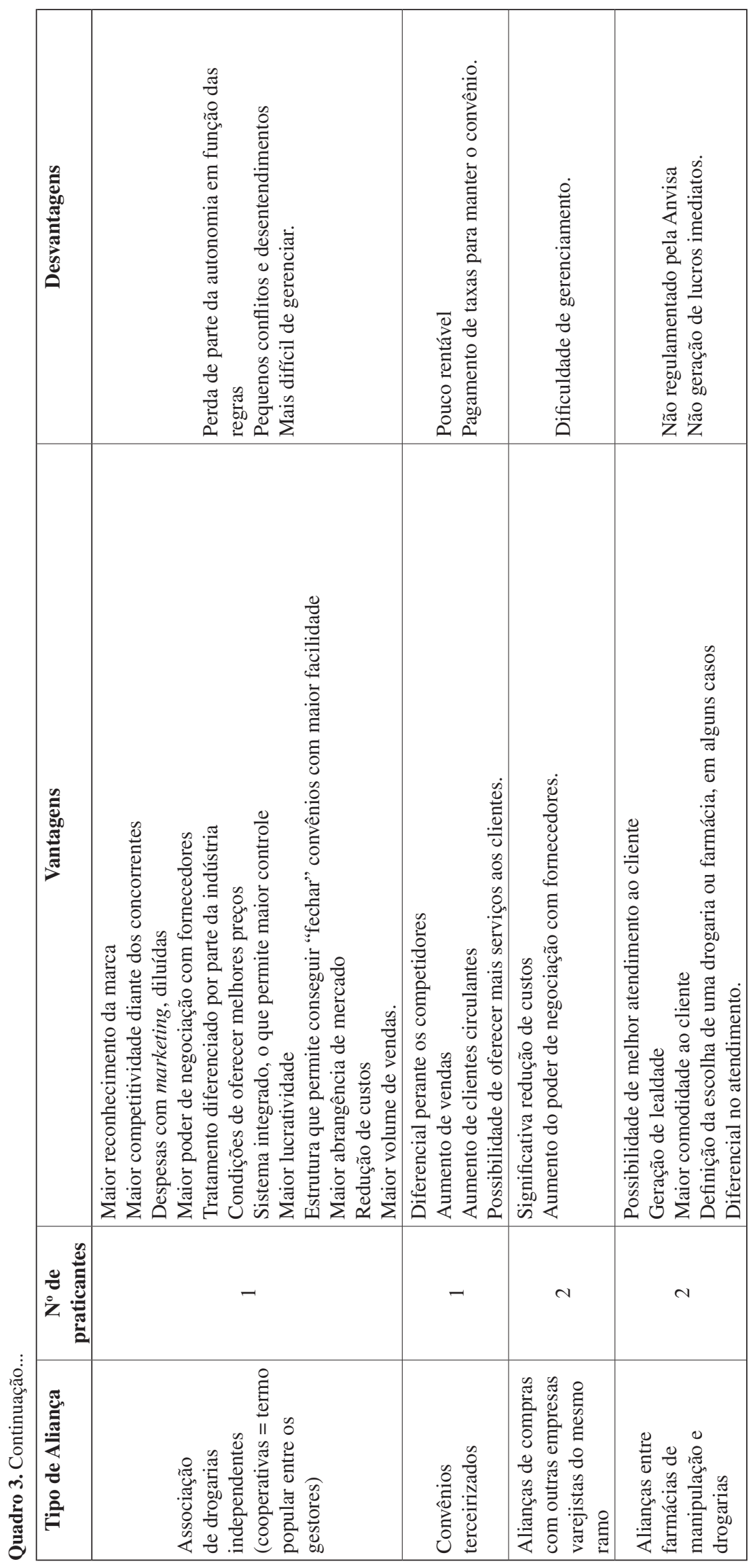


é apontado como uma vantagem. Esta vantagem é mais evidente nos casos em que é possível obter economia de escala, o que é mais comum nas compras compartilhadas ou associativismo, e também no estabelecimento de convênios e na aliança com fornecedores exclusivos. Eis algumas respostas por parte dos entrevistados: a) Sim, sim. Perante os fornecedores, porque fornecedor é basicamente isso, a partir do momento que você compra mais, você passa também a exigir alguma coisa; b) Sim, há mais fornecedores oferecendo itens em exclusividade (os primeiros, eles é que foram atrás) e os concorrentes estão muito incomodados.

Constatou-se que a aliança estratégica a partir de convênios próprios é uma prática comum em nove das dez farmácias e drogarias pesquisadas, por isso, os gestores não a consideram como uma forma de obter um diferencial competitivo.

Percebeu-se que para alguns gestores as vantagens da prática de convênios próprios não ficavam tão claramente explícitas. Muitos praticavam esta aliança porque os seus clientes pediam, mas, a partir da análise dos resultados, as vantagens deste tipo de estratégia, bem como seus benefícios, ficaram evidentes, destacando-se o aumento nas vendas. Vale ressaltar a importância dessa aliança para as pequenas drogarias independentes. $\mathrm{Na}$ amostra pesquisada, as empresas que praticavam convênios próprios atribuem a sua sobrevivência a esses acordos firmados, isto porque esta estratégia é o que garante a sobrevivência da drogaria independente diante da alta concorrência existente neste ramo de atuação.

Os convênios terceirizados, geralmente vinculados aos seguros saúde, são uma aliança pouco praticada pelas empresas que participaram deste estudo, entretanto, têm como vantagem gerar economia de escala (ver Figura 1), conforme assegurado por um dos respondentes: A concorrência em Bragança e Atibaia é muito forte; existem muitas drogarias competindo pela mesma fatia de mercado e isto faz com que as farmácias busquem alternativas para vender mais. É um mercado que basicamente compete por preço, e para oferecer preço baixo tem que comprar muito, só assim se consegue descontos. Então, os convênios e as outras alianças ajudam nesta questão do volume e preço.

$\mathrm{Na}$ aliança denominada como compartilhamento de compras, as vantagens apontadas pelos gestores são quanto à redução de custos e aumento do poder de barganha com fornecedores (Quadro 3), refletindo o que vários autores, tais como Collis e Montgomery (1997), Inkpen (2001) e Barney (2002) e Grant (2002), já haviam afirmado no sentido de que este tipo de aliança permite um rápido crescimento, maior velocidade de mercado, além de compartilhar custos e riscos inerentes ao tipo de mercado em que as empresas atuam.
Esta pesquisa demonstrou que a principal desvantagem dessa aliança é a dificuldade de gerenciamento por parte das empresas participantes, uma vez que o processo decisório conta com mais envolvidos e menor poder de decisão para cada empresa que participa dessa aliança estratégica, o que dificulta estabelecer objetivos comuns (COSTA, 2003; PITTS; LEI, 2003; WALKER, 2004).

Por outro lado, este tipo de aliança oferece maior flexibilidade na gestão e menos divergência de objetivos, o que tende a minimizar os fatores que colocam em risco as alianças, citados por Thompson e Strickland III (2001), tais como a divergência de objetivos e a inabilidade para trabalhar bem em conjunto.

$\mathrm{Na}$ aliança estratégica caracterizada pelo associativismo (associação de drogarias independentes), popularmente denominada cooperativa pelos gestores, percebeu-se o que Aaker (2001), Costa (2003), Pitts e Lei (2003) e Thompson e Strickland III (2001), afirmaram no sentido de que as alianças também permitem maior acesso ao mercado, impacto na estrutura da indústria e geração de economias de escala. Os resultados demonstraram que as empresas envolvidas nesse tipo de aliança possuíam melhores condições de negociação junto aos fornecedores.

Em contrapartida, os resultados da pesquisa demonstraram que o associativismo é uma aliança que gera conflitos administrativos, principalmente quanto a repasses de valores, e no que se refere ao processo decisório. Thompson e Strickland III (2001) afirmaram que, quando duas ou mais empresas se juntam, existe o enfraquecimento da identidade organizacional e sempre prevalece a mais forte. Pitts e Lei (2003), Costa (2003) e Walker (2004) ressaltam a desvantagem inerente à diminuição do controle que as alianças proporcionam às empresas envolvidas, pois quanto maior o número de envolvidos, menor o poder de cada um, e torna-se mais difícil firmar objetivos comuns. Esses pontos negativos ficaram explícitos ao se fazer a seguinte pergunta: Existe algum tipo de desentendimento entre os participantes? Em caso afirmativo, você poderia comentar? E uma das respostas foi: Pequenos desencontros nas compras em conjunto, quanto a datas de pedido, entrega e pagamentos, mas sempre chega-se a um acordo.

A aliança estratégica praticada a partir de acordos com fornecedores exclusivos apresentou duas vantagens citadas por Rugman e Wright (2001): fortalecimento de um negócio existente e introdução de produtos de uma empresa em novos mercados. Como desvantagem, evidenciou-se o enfraquecimento da identidade organizacional.

A última aliança praticada pelas farmácias e drogarias estudadas é denominada alianças entre farmácias de manipulação e drogarias, que apresenta 
como vantagem agregar valor à atividade do negócio. De acordo com Lowson (2002), o valor está na combinação de produtos e serviços que atendam às necessidades e escolhas dos clientes. Nesse sentido, esse tipo de aliança geralmente ocorre entre farmácias de manipulação e drogarias e, conforme um dos respondentes, agrega valor ao cliente à medida que, por exemplo, um indivíduo vai numa drogaria e ele tem uma receita lá onde tem quatro itens, dois são de drogaria, dois são manipulados, e a drogaria muitas vezes, pra atender o seu cliente, liga pra gente e pede: olha, preciso de dois produtos manipulados tal..., a gente entrega pra ele ou ele vem retirar aqui, tal....., isso a gente tem com várias drogarias na...na... cidade onde eu estou instalado, em Bragança como em Atibaia, por exemplo, que é uma cidade perto,... facilitar a vida do cliente dele, em vez do cliente ir em dois, três lugares ele só vai lá......

\section{Considerações finais}

O objetivo deste trabalho foi ampliar a compreensão do movimento competitivo que tem se desenvolvido no varejo farmacêutico por meio da identificação das alianças estratégicas que estão sendo praticadas pelo setor e as vantagens e desvantagens de cada uma delas.

Como pano de fundo para a formação das alianças, está o fato de o mercado nacional ser, por um lado, bastante atrativo, com taxa de crescimento anual em torno de dois dígitos e perspectiva de crescimento, devido ao interesse crescente dos consumidores em adquirir, também, cosméticos por este canal; mas, por outro lado, o mercado brasileiro de farmácias é muito pulverizado.

As alianças estratégicas têm sido a solução encontrada pelo varejo para garantir as melhores margens de preço. O mercado apresenta um movimento no sentido da consolidação, com as grandes redes praticando as estratégias de fusão e aquisição. Pode-se inferir que, para as grandes empresas, as alianças são um meio de aumentar o poder de barganha junto aos fornecedores e a barreira de entrada aos novos competidores.

O estudo foi realizado no pequeno varejo e foram identificados outros tipos de alianças: franquias, convênios próprios, fornecedores exclusivos, associativismo, convênios terceirizados, alianças de compras com outras empresas varejistas do mesmo ramo e alianças entre farmácias de manipulação e drogarias.

No mercado analisado, até onde se pôde apurar, não foram identificadas barreiras de entrada ou vantagens competitivas específicas e, de acordo com o relato dos respondentes, as margens de lucro são pequenas, devido ao elevado número de competidores.

Por isso, um dos principais fatores citados pelos varejistas e que impulsiona a necessidade de aumentar a competitividade é: o consumo de medicamentos é permeado pela sensibilidade ao preço por parte dos consumidores, sendo, portanto, a diminuição de custos o principal fator que leva à formação de alianças. Os varejistas praticam as alianças com o objetivo de ganhar economia de escala e ter margem para praticar preços inferiores ao concorrente. Esse objetivo pode estar explícito, como no caso do associativismo, ou implícito, como no caso dos convênios próprios, que garantem maior volume de vendas.

Em geral, os resultados confirmam as afirmações teóricas sobre as vantagens e desvantagens de cada tipo de aliança e representam, portanto, uma contribuição para a consolidação dessas propostas. Do ponto de vista da realidade organizacional, esse conhecimento pode servir de base para o aprimoramento do processo de tomada de decisão sobre formação de alianças devido à incerteza, interdependência e vulnerabilidade envolvidas.

Os gestores concordam com a afirmação teórica de que a formação de alianças agrega valor às atividades da farmácia ou drogaria, proporciona maior acesso ao mercado e rápido crescimento. Uma análise cruzada das principais vantagens e desvantagens relatadas pelos gestores demonstra que alguns fatores são comuns a mais de um tipo de aliança.

- Franquias e cooperativas são as mais afetadas quanto à diminuição no controle das operações, devido ao número de pessoas envolvidas na gestão (COSTA, 2003; PITTS; LEI, 2003; WALKER, 2004);

- O direcionamento estratégico pode se tornar mais lento e engessado, devido à alta dependência entre os envolvidos na aliança (COSTA, 2003; WALKER, 2004), no caso das franquias, cooperativas, alianças com fornecedores exclusivos e alianças de compras compartilhadas com outras farmácias e drogarias;

- A diminuição dos custos, devido a economias de escala, é mais facilmente obtida nas alianças para compartilhamento de compras, cooperativas e aliança com fornecedores exclusivos.

Os gestores entrevistados, mesmo vivenciando as dificuldades relatadas, esperam que as alianças estratégicas garantam a competitividade de suas empresas.

Alguns fatores identificados, tais como perda de autonomia, falta de agilidade, conflitos no estabelecimento de objetivos, são indicativos de que pode existir um crescimento de incompatibilidade entre os parceiros, como apontado por Collis e Montgomery (1997) e Pitts e Lei (2003).

Segundo Creswell (2007), a proposição dos estudos qualitativos não é a de generalizar as descobertas, mas de prover uma interpretação única dos eventos, o que não impediria que generalizações limitadas pudessem ser discutidas. 
No entanto, não se recomenda a generalização dos resultados obtidos, em primeiro lugar, devido à natureza exploratória da pesquisa, uma vez que as alianças são ainda um fenômeno muito recente no setor. As farmácias independentes, por exemplo, ainda representam mais de $90 \%$ do total das farmácias brasileiras (TAMASCIA, 2010). Outro fator são as condições específicas do ambiente competitivo, no qual essas farmácias estão inseridas, que afetam o grau de rivalidade e as razões para a busca das alianças.

Sugere-se, no entanto, que outros estudos sejam desenvolvidos, aumentando o número de empresas participantes, como estudos quantitativos destinados a confirmar ou ampliar os fatores levantados neste estudo. Também seria pertinente elaborar uma pesquisa qualitativa junto às grandes redes de drogarias, para ampliar a visão sobre o movimento competitivo do setor, os tipos de alianças que estão sendo praticadas e seus benefícios.

\section{Referências}

AAKER, D. A. Administração Estratégica de Mercado. Porto Alegre: Bookman, 2001.

AMORIM, L. As grandes farmácias vão ficar enormes. Revista Exame, ed. 1011, 07 mar. 2012. Disponível em: <http:// exame.abril.com.br/revista-exame/edicoes/1011/noticias/ as-grandes-farmacias-vao-ficar-enormes?page $=2$ \&slug_ name $=$ as-grandes-farmacias-vao-ficar-enormes $>$. Acesso em: 20 ago. 2012.

AGÊNCIA NACIONAL DE VIGILÂNCIA SANITÁRIA - ANVISA. Lei no 5.991, de 17 de dezembro de 1973. Dispõe sobre o Controle Sanitário do Comércio de Drogas, Medicamentos, Insumos Farmacêuticos e Correlatos, e dá outras Providências. Diário Oficial da República Federativa do Brasil, Brasília, DF, 19 dez. 1973. Disponível em: <http://www.anvisa.gov. br/legis/leis/5991_73.htm>. Acesso em: 28 jun. 2011.

BARDIN, L. Análise de conteúdo. Lisboa: Edições 70, 1977.

BARNEY, J. B. Gain and sustaining competitive advantage. Upper Siddle River: Prentice-Hall, 2002.

BARRETO, S. M. O rumo das farmácias brasileiras. Folha de S. Paulo, São Paulo, 20 jul. 2012. Opinião. Disponível em: <http://www1.folha.uol.com.br/fsp/ opiniao/55466-o-rumo-das-farmacias-brasileiras.shtml>. Acesso em: 20 ago. 2012.

BUZÁDY, Z. Which club does your alliance belong to? An empirical classification of strategic alliances in post-transition Hungary. Journal for East European Management Studies, v. 10, n. 2, p. 131-155, 2005.

CARMO, J. Vendas de produtos de higiene e beleza crescem 30\%. Núcleo de estudos do varejo da ESPM, maio 2011. Disponível em: <http://varejo.espm.br/1310/ vendas-de-produtos-de-higiene-e-beleza-crescem-30>. Acesso em: 20 ago. 2012.

CONSELHO FEDERAL DE FARMÁCIA. Estabelecimentos Farmacêuticos no Brasil. Disponível em: <http://www.cff.org.br>. Acesso em: 20 ago. 2012.

CONSELHO REGIONAL DE FARMÁCIA DO ESTADO DE SÃO PAULO. História da Farmácia. Disponível em: <http://www.crfsp.org.br/index.php/historia-dafarmacia-.html>. Acesso em: 30 jun. 2011.

COLlis, D. J.; MONTGOMERY, C. A. Corporate strategy: Resources and the scope of the firm. New York: McGrawHill, 1997.

COSTA, E. A. Gestão Estratégica. São Paulo: Saraiva, 2003. CRESWELL, J. W. Projeto de pesquisa: métodos qualitativo, quantitativo e misto. Porto Alegre: Artmed, 2007.

FITZPATRICK, W. M.; DILULLO, S. A. Strategic alliances and the management of intellectual properties: The art of contract. S.A.M. Advanced Management journal, v. 70, n. 3, p. 38-45, Summer 2005.

GRANT, R. M. Contemporary strategy analysis: Concepts, techniques, applications. Oxford: Blackwell, 2002.

HILL, C. W. L.; JONES, G. R. Strategic management: An integrated approuch. Boston: Houghton Mifflin Company, 1998.

IMS HEALTH CONSOULTING. Saiba o que impulsiona o Mercado Farmacêutico Brasileiro. IMS Health Incorporated, 2012. Disponível em: <http://www. imshealth.com/portal/site/ims/menuitem.d248e29c8 6589c9c30e81c033208c22a/?vgnextoid=5f0ceb697 $3858310 \mathrm{VgnVCM} 10000076192 \mathrm{ca} 2 \mathrm{RCRD}>$. Acesso em: 20 ago. 2012.

INKPEN, A. C. Strategic alliances. In: HITT, M. A.; FREEMAN, R. E.; HARRISON, J. S. (Org.). The blackwell handbook of strategic management. Oxford: Blackwell Publishers, 2001.

JACOBSEN, L. R. Whither franchising? The case of avis europe PLC. Managerial and Decision Economics Journal, v. 25, p. 525, 2004. http://dx.doi.org/10.1002/ mde. 1183

JACKSON, I. A.; NELSON, J. Value-driven performance: Seven strategies for delivering profits with principles. Ivey Business Journal Online, p. B1, Nov/Dec 2004.

KÖCHE, J. C. Fundamentos de metodologia científica: Teoria da ciência e prática da pesquisa. Petrópolis: Vozes, 1999.

LEVY, M.; WEITZ, B. A. Administração de varejo. São Paulo: Atlas, 2000.

LIU, W. K. Advantage Competition of Inter-Partner Learning in International Strategic Alliance. Journal of Global Business Issues, v. 3, n. 2, p. 123-128, Summer 2009.

LOWSON, R. H. Strategic operations management: The new competitive advantage. London: British Library Cataloguing in Publication Data, 2002. http://dx.doi. org/10.4324/9780203361528

MacGREGOR, R. C.; VRAZALIC, L. The effects of strategic alliance membership on the disadvantages of eletronic - commerce adoption: A comparative study of Swedish and Australian regional small business. Journal of Global Information Management, v. 13, n. 3, p. 1-19, Jul/Sept 2005. http://dx.doi.org/10.4018/ jgim.2005070101

MACHLINE, C.; AMARAL JUNIOR, J. B. C. Avanços logísticos no varejo nacional: $\mathrm{O}$ caso das redes de farmácias. Revista de Administração de Empresas, v. 38, n. 4, p. 63-71, Out./Dez. 1998.

NIELSEN COMPANY. Evolução do Canal farma. Nielsen Company, 2010. Disponível em: <http://br.nielsen.com/ 
pubs/documents/Canal_farma_jul2010.pdf>. Acesso em: 20 ago. 2012.

NORDIN, F. Managing the process of adopting service logic in collaboration with suppliers. Journal of Change Management, v. 4, n. 4, p. 339-350, Dec 2004. http:// dx.doi.org/10.1080/14690701042000313126

OJODE, L. The impact of horizontal strategic alliances on the U.S. steel industry. Journal of Business Strategies, v. 21, n. 2, p. 149-178, Fall 2004.

PITTS, R. A.; LEI, D. Strategic management: Building and sustaining competitive advantage. Thomson Learning, 2003.

PORTER, M. E. Vantagem competitiva: Criando e sustentando um desempenho superior. Rio de Janeiro: Elsevier, 1989.

PRATER, E.; GHOSH, S. Current operational practices of U.S. small and medium-sized enterprises in Europe. Journal of Small Business Management, v. 43, n. 2, p. 155-169, Apr 2005. http://dx.doi. org/10.1111/j.1540-627x.2005.00131.x

RANFT, A. L.; MARSH, S. J. Assessing Knowledge through Acquisitions and Alliances: An Empirical Examination of New Market Entry. Journal of Management Issues, v. 20, n. 1, p. 51-67, 2008.

RATTEN, V. The role of learning and information dissemination in logistics alliances. Asia Pacific Journal of Marketing and Logistics, v. 16, n. 4, p. 65-81, 2004. http://dx.doi.org/10.1108/13555850410765276
RUGMAN, A. M.; WRIGHT, R. W. Research global strategic management. New York: Elsevier Science, 2001. PMid:11584622.

SHAO, G. Venturing Through Acquisitions or Alliances? Examining U.S. Media Companies' Digital Strategy. Journal of Media Business Studies, v. 7, n. 1, p. 21-39, 2010.

TAMASCIA, E. Varejo Independente tem que se profissionalizar para reverter concentração de mercado. FEBRAFAR, 2010. Disponível em: <http:// www.febrafar.com.br/index.php?cat_id=8\&pag_ id=7002 . Acesso em: 30 jun. 2011.

TAMASCIA, E. O paradoxo de um mercado em franca expansão. FEBRAFAR, 2012. Disponível em: <http:// www.febrafar.com.br/index.php?cat_id=8\&pag_ $\mathrm{id}=7878$ > . Acesso em: 20 ago. 2012.

TENG, B. S. Corporate Entrepreneurship Activities Through Strategic Alliances: A Resource-Based Approach toward Competitive Advantage. Journal of Management Studies, v. 44, n. 1, p. 119-142, Jan 2007. http://dx.doi. org/10.1111/j.1467-6486.2006.00645.x

THOMPSON, A. A.; STRICKLAND III, A. J. Strategic management: Concepts and cases. New York: McGrawHill, 2001.

VASCONCELOS, F.; BRITO, L. A. L. Vantagem competitiva: $O$ construto e a métrica. Revista de Administração de Empresas, p. 51-63, abr./jun. 2004. WALKER, C. Modern competitive strategy. New York: McGrawHill, 2004. 